\title{
Systematic review of defibrotide studies in the treatment of veno- occlusive disease/sinusoidal obstruction syndrome (VOD/SOS)
}

\author{
Paul Richardson ${ }^{1} \cdot$ Saurabh Aggarwal ${ }^{2}$ - Ozlem Topaloglu ${ }^{2} \cdot$ Kathleen F. Villa ${ }^{3} \cdot$ Selim Corbacioglu ${ }^{4}$
}

Received: 21 August 2018 / Revised: 20 December 2018 / Accepted: 20 January 2019 / Published online: 25 February 2019

(c) The Author(s) 2019. This article is published with open access

\begin{abstract}
Veno-occlusive disease (VOD), also called sinusoidal obstruction syndrome (SOS), is a potentially life-threatening complication of hematopoietic stem cell transplantation (HSCT) conditioning or high-dose nontransplant chemotherapy. VOD/SOS with multi-organ dysfunction (MOD) is associated with a mortality rate of $>80 \%$. Defibrotide $(25 \mathrm{mg} / \mathrm{kg} / \mathrm{day})$ is approved to treat hepatic VOD/SOS with renal or pulmonary dysfunction post HSCT in the United States and to treat severe hepatic VOD/SOS in patients $>1$ month of age in the European Union. A random effects model was used for pooling data from 17 systematically chosen defibrotide studies. For patients in these reports $(n=2598)$, and those in the subset of 10 reports of patients treated with $\sim 25 \mathrm{mg} / \mathrm{kg} /$ day $(n=1691)$, estimated Day +100 survival rates were $54 \%$ and $56 \%$, respectively. Among those patients treated with $\sim 25 \mathrm{mg} / \mathrm{kg} /$ day, estimated Day +100 survival was $44 \%$ among patients with MOD and $71 \%$ in patients without MOD; survival was $41 \%$ and $70 \%$, respectively, for the population of patients receiving any dose of defibrotide. Safety results were not pooled owing to differences in reporting methodology but were generally consistent with the known tolerability profile of defibrotide. This analysis provides the largest assessment of survival in patients treated with defibrotide for VOD/SOS with or without MOD.
\end{abstract}

\section{Introduction}

Hepatic veno-occlusive disease (VOD), also called sinusoidal obstruction syndrome (SOS), is a potentially lifethreatening complication of conditioning regimens for hematopoietic stem cell transplantation (HSCT) and also of chemotherapy alone [1-4]. Risk factors may be related to transplant (eg, the toxicity of chemotherapy or the conditioning regimen, allogeneic vs autologous transplant, immunosuppressive regimen), patient characteristics (eg, age, underlying disease, genetic predisposition), and health

Saurabh Aggarwal

sa2@novelhealthstrategies.com

1 Jerome Lipper Multiple Myeloma Center, Division of Hematologic Malignancy, Department of Medical Oncology, Dana-Farber Cancer Institute, Harvard Medical School, Boston, MA, USA

2 Novel Health Strategies, Bethesda, MD, USA

3 Jazz Pharmaceuticals, Inc, Palo Alto, CA, USA

4 Department of Pediatric Hematology, Oncology and Stem Cell Transplantation, University of Regensburg, Regensburg, Germany status of the liver (eg, immature liver function in infants, iron overload, liver fibrosis, hepatitis) [5, 6].

The pathogenesis of VOD/SOS involves multiple thrombotic and inflammatory factors that initially trigger damage to the endothelial cells lining the sinusoids of the hepatic acinus. Damaged endothelial cells may show cytopathic effects by rounding up, forming gaps in the sinusoidal barrier that allow passage of erythrocytes, leukocytes, and cellular debris into the space of Disse. As the venous lumen narrows and reduces the effluent from the sinus, postsinusoidal portal hypertension occurs and can progress to the clinical symptoms of VOD/SOS [5-8].

Diagnosis of VOD/SOS has historically been based on clinical examination by either Baltimore criteria (bilirubin $\geq$ $2 \mathrm{mg} / \mathrm{dL}$ plus 2 or more of hepatomegaly, ascites, or $\geq 5 \%$ weight gain by Day 21 post HSCT) [9] or modified Seattle criteria (two or more of the following: bilirubin $>2 \mathrm{mg} / \mathrm{dL}$, hepatomegaly or right upper quadrant pain, $2 \%$ weight gain [sometimes revised as $5 \%$ by Day 20 post HSCT [10]]) [11]. However, those criteria lack sensitivity and specificity, making early identification of VOD/SOS difficult. In addition, particularities in the presentation of VOD/SOD in children are not reflected in these diagnostic criteria. More recently, the European Society for Blood and Marrow 
transplantation (EBMT) has proposed new diagnostic guidelines and prospective severity grading criteria for adults and for children [7,8]. The adult diagnostic criteria from EBMT encompass classical VOD/SOS as defined by Baltimore criteria but also include late-onset VOD/SOS (VOD/SOS developing after 21 days post HSCT). The new pediatric diagnostic criteria from EBMT include differences from the traditional criteria, such as having no defined timeframe of onset and the presence of unexplained consumptive/transfusion-refractory thrombocytopenia, otherwise unexplained weight gain for 3 consecutive days despite diuretic use, and rising bilirubin from baseline value on 3 consecutive days or bilirubin $\geq 2 \mathrm{mg} / \mathrm{dL}$ within $72 \mathrm{~h}$. These new diagnostic guidelines are designed to support earlier diagnosis and treatment with greater specificity, and to highlight substantial differences in presentation between adult and pediatric patients (eg, anicteric presentation in $30 \%$ of children which may be less common in adults presenting by Day 21 post HSCT) [7, 8].

VOD/SOS develops in $\sim 10-15 \%$ of adult patients who receive myeloablative conditioning followed by allogeneic HSCT $[1,5,12,13]$. In patients receiving autologous HSCT or reduced intensity conditioning with allogeneic HSCT, incidence may be $\sim 5 \%$ [14], although a rate of $8.8 \%$ postreduced intensity conditioning was reported in the past few years by one center [15]. Overall incidence in pediatric patients post HSCT has been reported between 22 and $30 \%$, and in high-risk pediatric patients may increase to $60 \%$ [8]. The incidence in pediatric patients of VOD/SOS postautologous HSCT for neuroblastoma is $\sim 30 \%$, likely owing to a busulfan-melphalan myeloablative conditioning [8].

VOD/SOS with multi-organ dysfunction (MOD; typically defined by renal and/or pulmonary dysfunction and sometimes referred to as multi-organ failure) may be associated with survival of $20-30 \%$ in HSCT patients receiving supportive care alone [1, 3, 4].

Owing to the progressive pathophysiology of VOD/SOS and the high mortality associated with VOD/SOS and MOD, the EBMT recommends that early diagnosis and treatment of VOD/SOS should be a priority, and they note that the "only proven" treatment is defibrotide [5]. For adult and pediatric patients, defibrotide $(25 \mathrm{mg} / \mathrm{kg} /$ day intravenously in four divided doses) is approved to treat hepatic VOD/SOS with renal or pulmonary dysfunction post HSCT in the United States [16], and to treat severe hepatic VOD/ SOS post HSCT in patients over 1 month of age in the European Union [17]. Defibrotide's mechanism of action, as elucidated in preclinical studies, centers on protection of endothelial cells and anti-inflammatory effects, which together help restore thrombo-fibrinolytic balance [18-23].

To provide an estimate of overall survival in patients with VOD/SOS treated with defibrotide, we pooled systematically collected Day +100 survival analysis data from published studies on the use of defibrotide to treat patients with VOD/SOS, post HSCT or post-nontransplant chemotherapy, with or without MOD.

\section{Materials and methods}

\section{Search criteria}

A systematic review of Medline and Medline In-Process for journal articles, and Embase for journal articles and conference abstracts, until July 10, 2017, was performed per a prespecified and clearly defined protocol based on Preferred Reporting Items for Systematic Reviews and MetaAnalyses (PRISMA) guidelines. Owing to the lag time of 3-6 months for conference abstracts in Embase, abstracts from the more recent 2017 EBMT and European Hematology Association meetings were also searched using the conference websites. The search term for all databases was "defibrotide" in the title or abstract. Duplicate results from these searches were removed.

\section{Criteria for study selection}

Prospective and retrospective studies of defibrotide for treatment of VOD/SOS post HSCT or post-nontransplant chemotherapy were selected for inclusion. Excluded were reviews, prophylaxis or prevention studies, post hoc analyses, nonclinical studies, letters, clinical studies without primary efficacy data, no defibrotide treatment, and use in patients without VOD/SOS. Results from the initial keyword literature searches were screened, and full-length text for each report was evaluated for eligibility.

\section{Data collection}

Full versions of the selected studies were assessed to determine study design, sample size, dose, treatment duration, patient characteristics (age, post-transplant or postchemotherapy onset, and underlying disease), comparator(s), Day +100 survival, and safety outcomes. When necessary, subgroup data were sourced from clinical study reports. For case series reporting patient-level data, the overall efficacy outcomes were estimated. Where reported, patients were divided into subgroups to analyze data for those with and without MOD, and for adult and pediatric patients.

\section{Biostatistical analysis}

A random effects model was used for pooling data for survival. Interstudy heterogeneity was assessed with Cochran's Q-test. The percentage of total variation across studies owing to heterogeneity was evaluated by the $I^{2}$ 


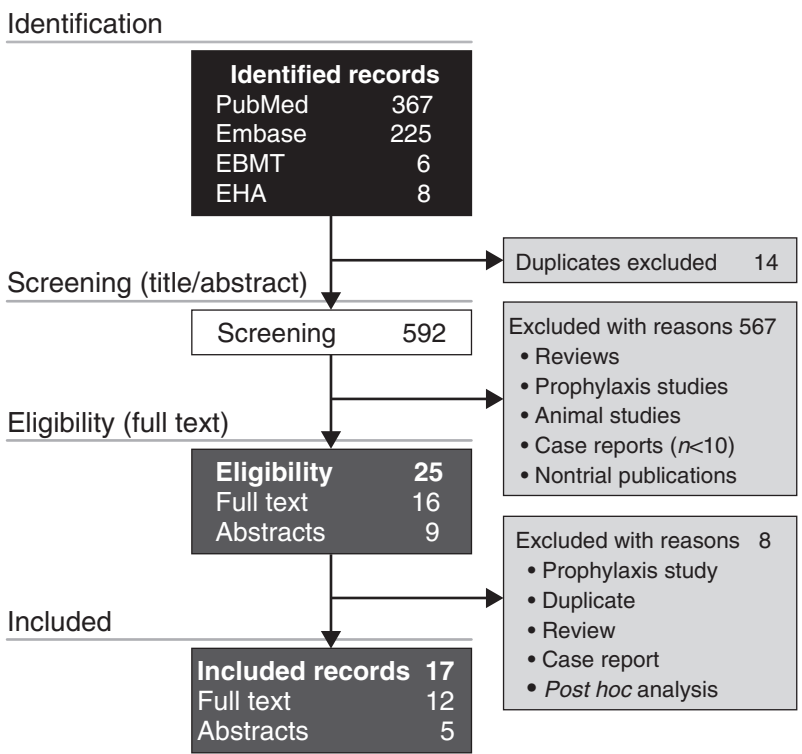

Fig. 1 Study selection

measure. Owing to differences in defining and reporting adverse events (AEs) in the individual studies, pooling the data may have been misleading; therefore, safety was evaluated qualitatively. Pooled survival was estimated using StataSE software (StataCorp, College Station, TX).

\section{Results}

The literature search based on the keyword "defibrotide" identified a total of 606 publications, which included 367 PubMed records, 225 Embase records, and 14 abstracts from the EBMT and European Hematology Association conferences (Fig. 1). Duplicates from these searches were removed.

After screening titles and abstracts for exclusion criteria, the remaining 25 complete records (16 full-text articles and nine conference abstracts) were analyzed and further refined by excluding eight reports that were post hoc analyses, reviews, duplicates, case reports, or a prevention trial. The 17 records chosen for pooled analysis were 12 full-length articles [3, 4, 24-33] and five abstracts [34-38] (Table 1). The study quality and types included retrospective case studies, single-center studies, registry reports, prospective multicenter compassionate use and treatment IND studies, and prospective multicenter two-arm phase 2 and 3 studies (Table 1). Patient ages ranged from 0.1 to 77 years, with median ages of 8.2-60.5 years. The combined studies included $2598 \mathrm{VOD} / \mathrm{SOS}$ patients treated with defibrotide, 1260 of whom had MOD (the precise definition of MOD varied among the studies). Most patients with VOD/SOS had received HSCT, and the most common primary diseases were acute leukemias [3, 4, 24, 26-33, 35, 37, 38]
(Table 1). Defibrotide doses ranged from $5 \mathrm{mg} / \mathrm{kg} /$ day to $110 \mathrm{mg} / \mathrm{kg} /$ day, and the duration of defibrotide treatment ranged from 1-139 days with median duration ranging from 14-21.5 days (Table 2). Ten of the 17 reports included patients treated with approximately the approved $25 \mathrm{mg} / \mathrm{kg} / \mathrm{day}$ defibrotide dose $(n=1691)$ [3, 25-27, 30, 34-38]. Seven of the 17 reports included other dosages, or the dosage was not reported [4, 24, 28, 29, 31-33].

\section{Efficacy}

The estimated Day +100 survival rate for 2598 patients receiving defibrotide at any dose across all studies [3, 4, 24-38] was 54\% (Fig. 2a), and a 56\% rate was shown among the 1691 patients in 10 reports of treatment at $\sim 25 \mathrm{mg} / \mathrm{kg} /$ day (Fig. $2 \mathrm{~b}$ ) [3, 25-27, 30, 34-38].

Pooled subgroup results showed that patients with MOD $(n=1260)$ who received any of the defibrotide doses [3, 27, 28, 30, 31, 33, 35, 36, 38] had an estimated Day + 100 survival rate of $41 \%$ (Fig. 3a), and a $44 \%$ rate was shown in the $\sim 25 \mathrm{mg} / \mathrm{kg} /$ day subgroup ( $n=792$; Fig. $3 \mathrm{~b}$ ) $[3,27,35,36,38]$.

Among the subgroup of patients without MOD $(n=941)$ receiving defibrotide at any dose [30-32, 35, 38], estimated Day +100 survival was $70 \%$ for those receiving any dose (Fig. 3c), and $71 \%$ in those receiving $\sim 25 \mathrm{mg} / \mathrm{kg} /$ day $(n=$ 565; Fig. 3d) [35, 38].

The pediatric subgroup was defined as patients aged $\leq 16$ years in three studies $[3,4,38]$ and $\leq 18$ years in five studies $[27,28,30,31,35]$. Pediatric patients with VOD/SOS, regardless of MOD status and dose $(n=1036)[3,4,27,28$, $30,31,35,38]$ had an estimated Day +100 survival rate of $60 \%$ (Fig. 4a), whereas the subgroup that received $\sim 25 \mathrm{mg} /$ $\mathrm{kg} /$ day dose $(n=792)[3,27,30,35,38]$ had a $68 \%$ estimated Day +100 survival rate (Fig. 4b). Three of the 25 $\mathrm{mg} / \mathrm{kg} /$ day studies included patients with MOD, with pooled Day +100 survival of $58 \%$ (95\% CI: $51-66 \%$ ) [3, 27, 38].

Adults were defined as patients aged $>16$ years in six studies $[3,4,25,26,35,38]$ and as $>18$ years in five studies $[27,28,30,31,33]$. The adult subgroup, regardless of MOD status and dose $(n=1128)[3,4,25-28,31,33,35,38,39]$ had an estimated Day +100 survival rate of $45 \%$ (Fig. 4c), whereas the subgroup that received the defibrotide dose of $\sim 25 \mathrm{mg} / \mathrm{kg} /$ day $(n=773)$ [3, 25-27, 30, 35, 38] had an estimated Day +100 survival rate of $48 \%$ (Fig. $4 d$ ). Three of the $25 \mathrm{mg} / \mathrm{kg} /$ day studies included patients with MOD, with pooled Day +100 survival of $36 \%$ (95\% CI: $29-42 \%$ ) [3, 27, 38].

Safety results for the included reports are summarized in Table 3. Safety results were not pooled for these studies owing to differences in safety reporting methodology; however, the results of individual studies were generally 


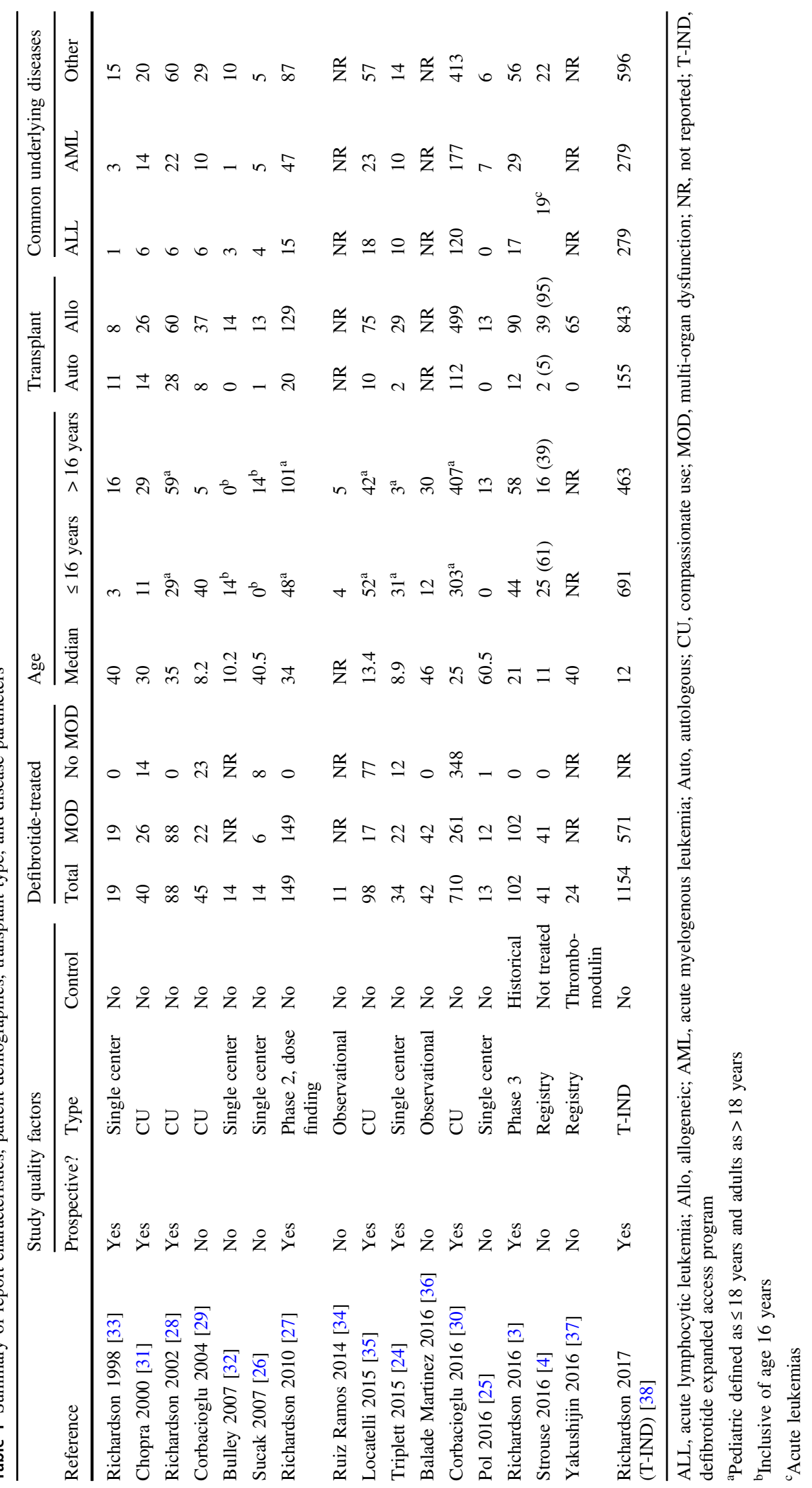




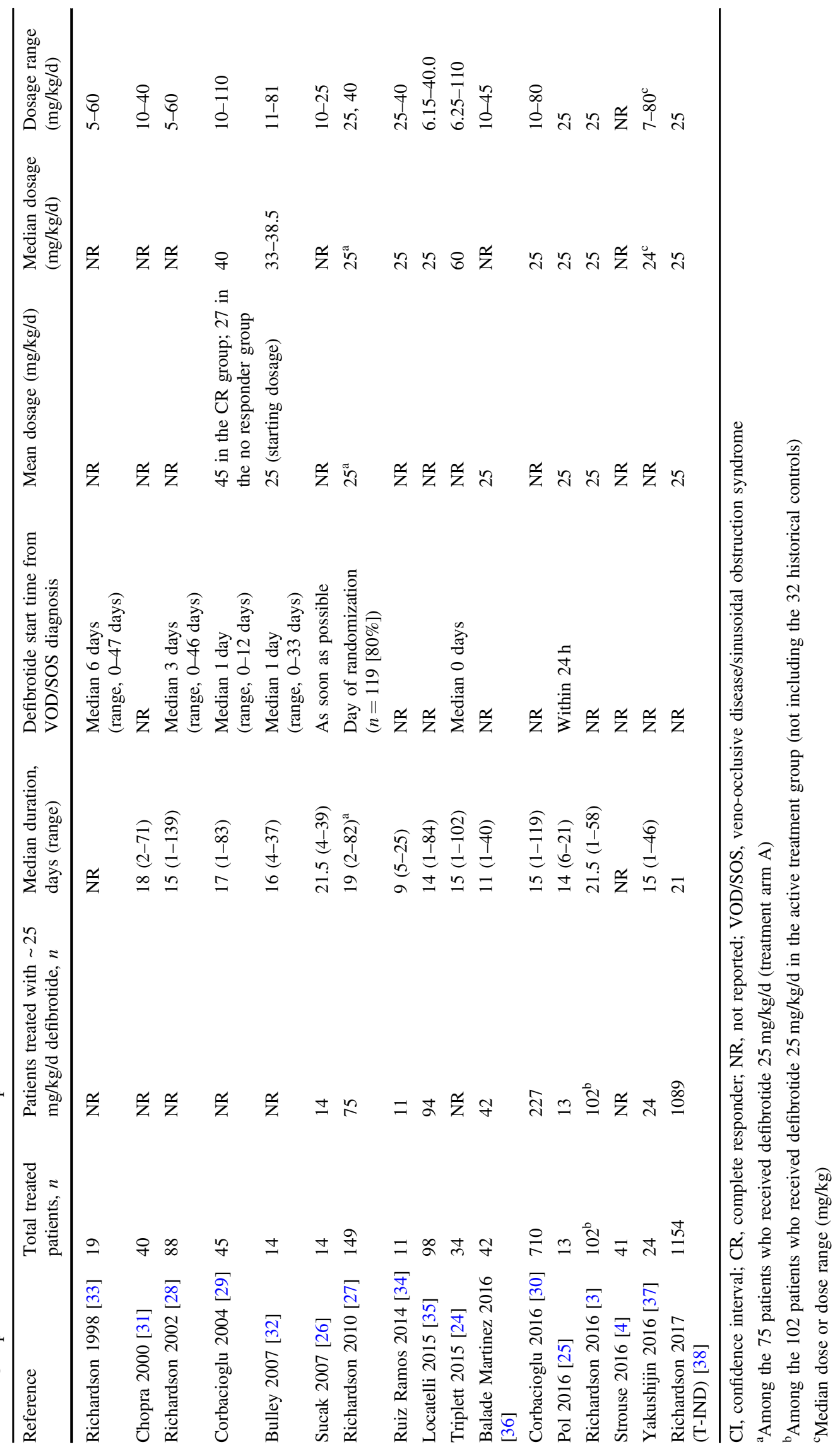


a

Patients treated with any dose of defibrotide

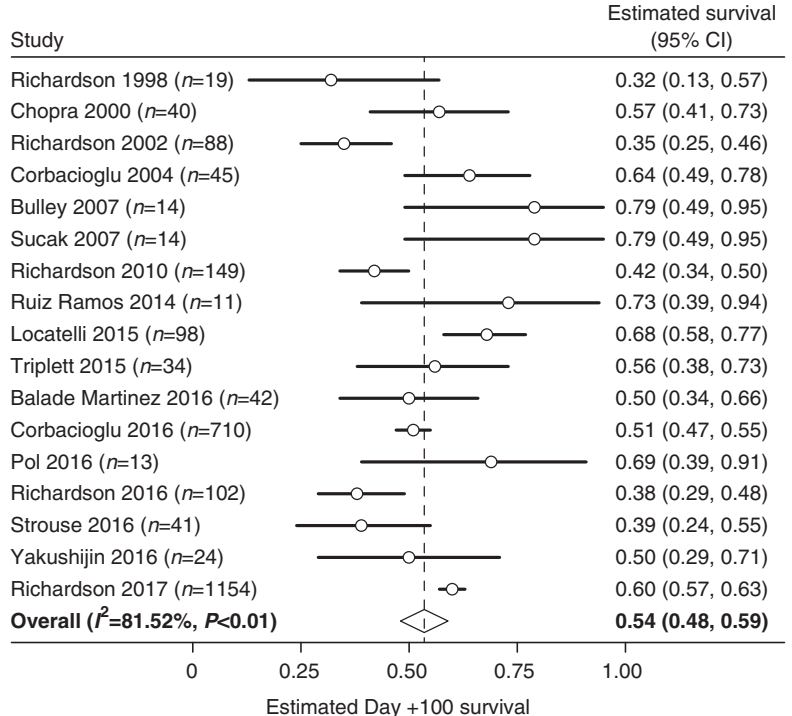

b

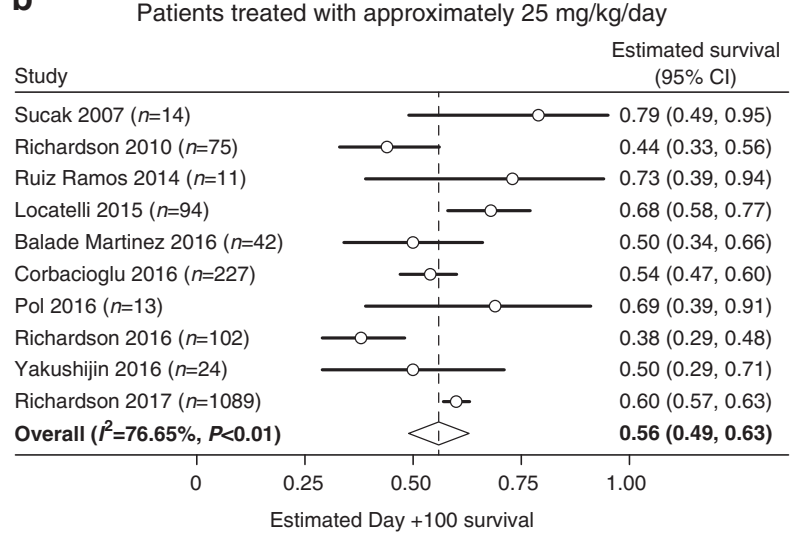

Fig. 2 Pooled analysis of the estimated Day +100 survival rates of the overall patient populations treated with any defibrotide dose or $\sim 25$ $\mathrm{mg} / \mathrm{kg} /$ day

consistent with the previously reported safety profiles, such as in the phase 3 historically controlled trial in VOD/SOS patients with MOD [3]. That trial reported that 101/102 defibrotide-treated patients and all 32 historical control patients experienced $\geq 1$ adverse event (AE). Hypotension was the most frequent $\mathrm{AE}$ (39\% for defibrotide, $50 \%$ for controls), and common hemorrhagic AEs, which included pulmonary alveolar and gastrointestinal hemorrhage, occurred in $64 \%$ of defibrotide-treated patients and $75 \%$ of controls. Treatment-related AEs in the defibrotide arm included hemorrhagic events and hypotension [3].

\section{Discussion}

This systematic, pooled analysis of currently available evidence for defibrotide efficacy in the treatment of patients a Patients with MOD treated with any dose of defibrotide

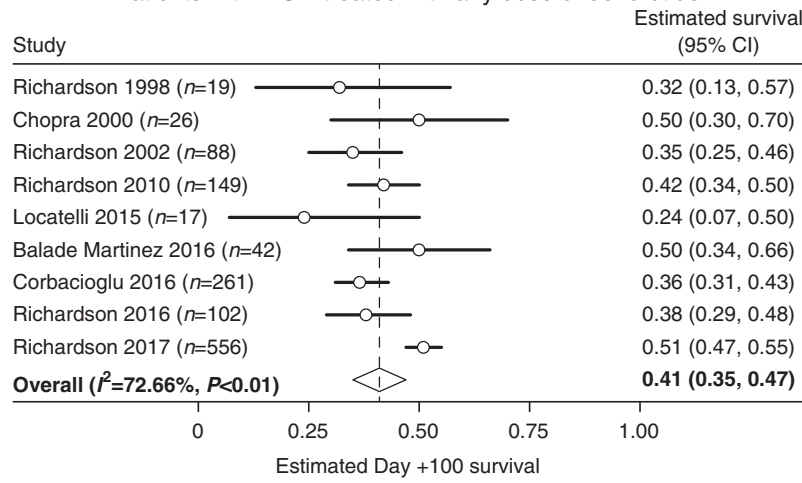

b Subgroup with MOD treated at $\sim 25 \mathrm{mg} / \mathrm{kg} /$ day

\begin{tabular}{|c|c|c|c|}
\hline \multicolumn{2}{|l|}{ Study } & & $\begin{array}{c}\text { Estimated survival } \\
(95 \% \mathrm{Cl})\end{array}$ \\
\hline Richardson 2010 ( $n=75)$ & $\longrightarrow$ & & $0.44(0.33,0.56)$ \\
\hline Locatelli $2015(n=17)$ & - & & $0.24(0.07,0.50)$ \\
\hline Balade Martinez $2016(n=42)$ & 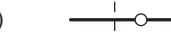 & & $0.50(0.34,0.66)$ \\
\hline Richardson 2016 ( $n=102)$ & $-\infty-\frac{1}{1}$ & & $0.38(0.29,0.48)$ \\
\hline Richardson 2017 ( $n=556)$ & $\infty$ & & $0.51(0.47,0.55)$ \\
\hline Overall $\left(I^{2}=68.49 \%, P=0.01\right)$ & & & $0.44(0.35,0.52)$ \\
\hline 0 & 0.25 & 0.75 & 1.00 \\
\hline
\end{tabular}

C

C Patients without MOD treated with any dose of defibrotide
Estimated survival
$(95 \% \mathrm{Cl})$

d Subgroup without MOD treated at $\sim 25 \mathrm{mg} / \mathrm{kg} / \mathrm{day}$

\begin{tabular}{llll} 
Study & & & $\begin{array}{c}\text { Estimated survival } \\
(95 \% \mathrm{Cl})\end{array}$ \\
\hline Locatelli $2015(n=77)$ & & &
\end{tabular}

Fig. 3 Estimated Day +100 survival for patients with MOD and without MOD

with VOD/SOS included 17 studies, representing 2598 patients. Estimated Day +100 survival rates in the 17 studies ranged from 35 to $79 \%$, and the pooled survival rate at Day +100 was $54 \%$. The approved $25 \mathrm{mg} / \mathrm{kg} /$ day dose was administered to patients in 10 of 17 studies $(n=1691)$, and its estimated survival rate at Day +100 was $56 \%$. This pooled analysis further supports the efficacy found for the $25 \mathrm{mg} / \mathrm{kg} /$ day dose of defibrotide in the phase 3 study [3] that was approved by regulatory authorities. 
a Pediatric patients treated with any dose of defibrotide

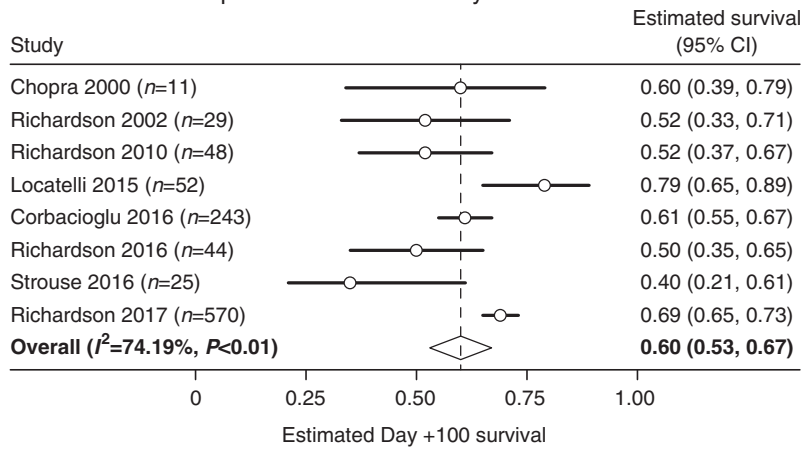

b

\section{b Pediatric subgroup treated at $\sim 25 \mathrm{mg} / \mathrm{kg} /$ day}

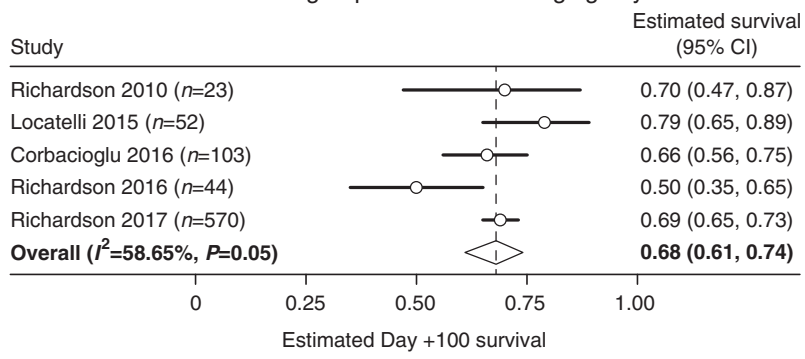

C

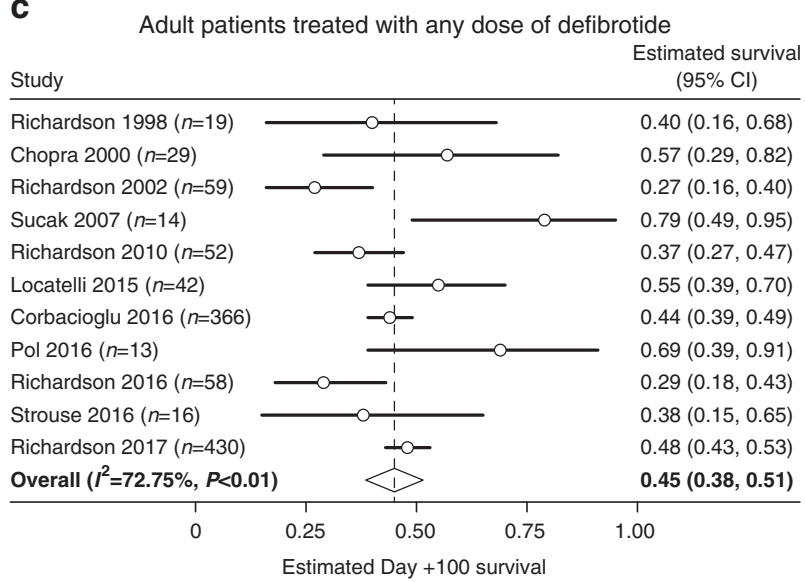

d

Adult subgroup treated at $\sim 25 \mathrm{mg} / \mathrm{kg} /$ day

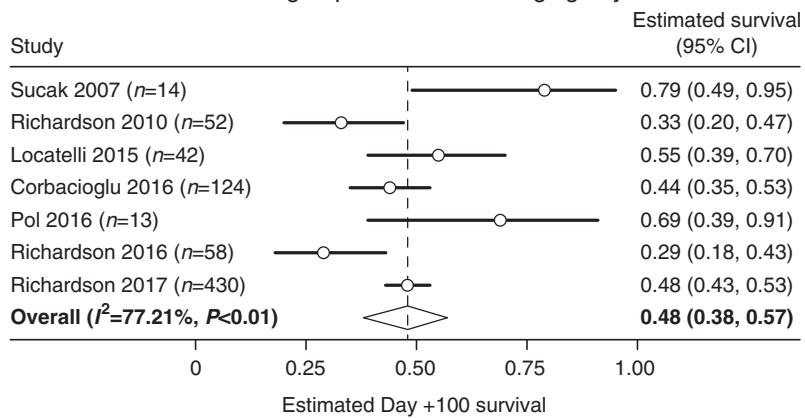

Fig. 4 Estimated Day +100 survival rates in pediatric and adult subgroups

Patients with VOD/SOS and MOD, regardless of treatment dose, had lower estimated survival rates at Day +100 than those without MOD: estimated survival rates for patients treated with any defibrotide dose or treated with the $\sim 25 \mathrm{mg} / \mathrm{kg} / \mathrm{day}$ defibrotide dose were $41 \%$ and $44 \%$, respectively. As points of comparison, Day +100 survival in the historical control population (rigorously selected owing to ethical concerns regarding withholding a supposed beneficial treatment from very sick patients with a dismal prognosis) in the phase 3 study was $25 \%$ [3], and in prior reports, patients with MOD who did not receive defibrotide were shown to have Day +100 survival results of $30.9 \%$ [4] and $15.7 \%$ [1]. Conversely, the estimated survival rates at Day +100 for patients without MOD were higher than those for the overall population: $70 \%$ for patients treated with any dose and $71 \%$ for those treated with $\sim 25 \mathrm{mg} / \mathrm{kg} / \mathrm{day}$. Of note, the definition of MOD varied among studies, and the large sponsored studies used a standard that represented the most severe forms (renal dysfunction typically defined by creatinine $\geq 3 \times$ level at time of transplant or creatinine clearance/glomerular filtration rate $\leq 40 \%$ of baseline, or dialysis dependence; pulmonary dysfunction typically defined by oxygen saturation $\leq 90 \%$ on room air or need for supplemental oxygen/ventilator dependence [3, 38]).

Estimated survival rates at Day +100 for pediatric patients with and without MOD, treated with any defibrotide dose or treated with the approximately $25 \mathrm{mg} / \mathrm{kg} /$ day defibrotide dose were $60 \%$ and $68 \%$, respectively, with $58 \%$ survival in the MOD subgroup receiving $25 \mathrm{mg} / \mathrm{kg} /$ day; in the T-IND study, survival at Day +100 for pediatric patients with MOD was 58.1\% [40]. In comparison, the US registry included in the pooled analysis also reported Day +100 survival among patients not receiving defibrotide to be $45.5 \%$ among pediatric patients with MOD [4].

Overall, estimated Day +100 survival rates for adults were $45 \%$ for those who received any dose and $48 \%$ for those receiving $\sim 25 \mathrm{mg} / \mathrm{kg} / \mathrm{day}$, with $36 \%$ survival in the MOD subgroup receiving $25 \mathrm{mg} / \mathrm{kg} /$ day; in the T-IND study, survival at Day +100 for adults with MOD was $39.0 \%$ [41]. In comparison, a Japanese registry of primarily adult patients ( $84.2 \%$ aged $\geq 16$ years), $95 \%$ of whom did not receive defibrotide, had a Day +100 survival rate of $32 \%$ in patients with and without MOD, and a rate of $15 \%$ in the MOD subgroup [13]. In the US registry, Day + 100 survival was $27.3 \%$ among adults with MOD not receiving defibrotide [4].

The AE reports for the 17 studies could not be pooled across studies owing to distinct reporting schemes. However, the overall AE profiles in the 17 studies were similar to those reported in the defibrotide phase 3 study [3]. In that study, AEs assessed by investigators as at least possibly related to defibrotide included hemorrhagic events and hypotension. Of note, however, overall rates of hypotension and hemorrhage (regardless of relatedness) were similar between arms. Hypotension was the most frequently 


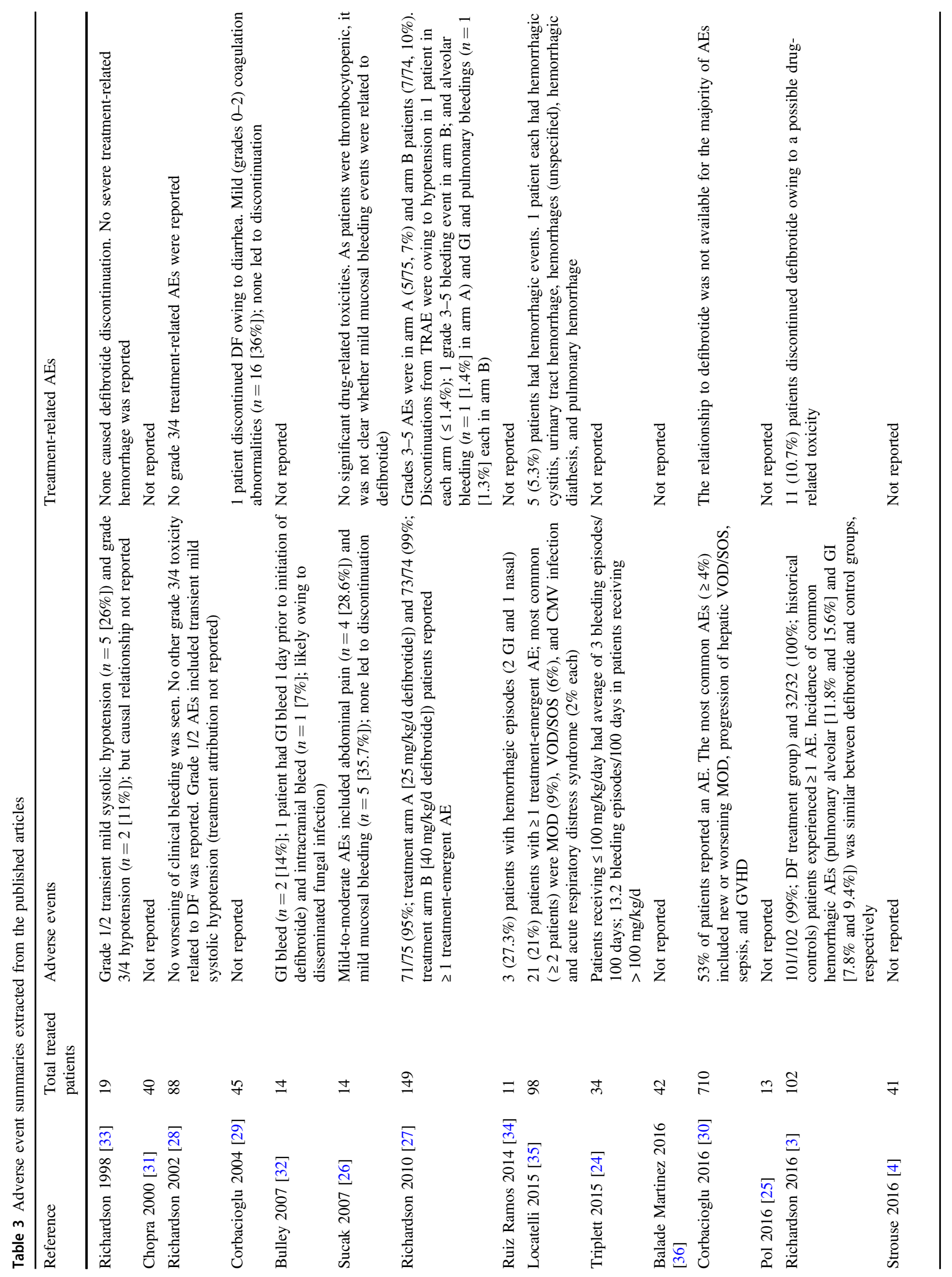


reported $\mathrm{AE}$ (39\% for defibrotide, $50 \%$ for controls), and hemorrhagic AEs, which included pulmonary alveolar hemorrhage $(11.8 \%$ vs $15.6 \%$, respectively) and gastrointestinal hemorrhage ( $7.8 \%$ vs $9.4 \%$, respectively), occurred in $64 \%$ of defibrotide-treated patients and $75 \%$ of controls [3].

Safety results from the two large single-arm studies, both of which included patients without MOD, found no novel AEs [30, 38]. Final results from the T-IND showed an AE rate of $70.2 \%$, with serious AEs reported in $51.8 \%$, whereas AEs considered treatment-related were most commonly hemorrhage (pulmonary, 4.3\%; gastrointestinal, 3.0\%; epistaxis, $2.3 \%$ ) and hypotension $(2.0 \%)$; serious treatmentrelated AEs occurred in $11.5 \%$ of patients [38]. In the compassionate use program, data reporting was not required owing to the nature of the study [30]. AEs were reported in $53 \%$ of patients, and causes of death (frequently reported as AEs) were primarily owing to progressive VOD/SOS with MOD.

A key strength of this analysis is that it represents the largest, most comprehensive review of Day +100 survival in patients with VOD/SOS who were treated with defibrotide. In most cases, however, patient-level data were not available to control for heterogeneity between studies, including differences in baseline characteristics, such as severity of MOD (eg, reduced pulmonary/renal function vs ventilator/dialysis dependence), which represents a limitation in that it was not possible to retrospectively apply the new severity criteria proposed by EBMT or to pool safety data. Another consideration in interpretation of these results is that the largest reports were from single-arm studies designed to provide access to defibrotide [30, 38]; however, the estimated Day +100 survival results are comparable to those of the phase 3 historically controlled trial (in patients with MOD only, with a propensity-adjusted numberneeded-to-treat of five to prevent one death) [3, 42, 43], and the safety profile in the phase 3 study helps illustrate the range of AEs associated with VOD/SOS and MOD irrespective of treatment with defibrotide.

The results in the patients without MOD may be supportive of treatment earlier in the pathophysiologic cascade of VOD/SOS. An exploratory analysis from the T-IND on the impact of timing of initiation with defibrotide on outcome found that earlier treatment initiation was associated with improved survival [44], which is consistent with what is known about the pathophysiologic cascade of VOD/SOS progression and the treatment recommendations from the EBMT [5]. Although mortality of VOD/SOS without prospectively identified MOD has not been well studied, a Japanese registry reported that VOD/SOS without MOD was associated with Day +100 mortality $>50 \%$ [13]. Indeed, prevention of development of both MOD and VOD/ SOS itself are important areas for research. At present, no 
medications are approved for the prevention of VOD/SOS, although defibrotide has been investigated in several studies [45-47] including a phase 3 study in pediatric patients, which suggest that defibrotide may reduce the risk for development of VOD/SOS compared with supportive care only (12\% vs $20 \%$ incidence, respectively; $P=0.0488$, competing risk analysis, $P=0.0507 \log$ rank test) [48]. Hemorrhage was the AE most commonly attributed by investigators to defibrotide; however, the incidence was similar between groups: $22 \%$ in the defibrotide arm and $21 \%$ in the control arm [49]. The HARMONY clinical trial (NCT02851407) to compare efficacy and safety of defibrotide versus best supportive care in the prevention of VOD/SOS in pediatric and adult patients is continuing to recruit patients [49]. Also, awareness of the importance of early intervention for improved outcomes may lead to a shift in the application of diagnostic criteria, from emphasis on the more exclusionary Baltimore and Seattle criteria to the more age-specific fit of the EBMT criteria. Finally, early use of magnetic resonance imaging for evaluating iron overload and/or ultrasound imaging to confirm such clinical criteria as ascites or hepatomegaly for VOD/SOS diagnosis and intervention may be of benefit to high-risk patients [5]. Elastographic methods also are under investigation to detect early markers of VOD/SOS, which may lead to earlier diagnosis and treatment [50].

In this pooled analysis of studies of defibrotide given approximately at the approved dose of $25 \mathrm{mg} / \mathrm{kg} /$ day for the treatment of VOD/SOS, estimated Day +100 survival was $56 \%$ in the 2073 patients with or without MOD. As expected, survival in patients with VOD/SOS without MOD was greater at Day $+100(69 \%)$ than in patients with VOD/ SOS with MOD (42\%). Safety results in the individual studies were generally consistent with the known safety profile of defibrotide. Taken together, these results show a largely consistent treatment effect for defibrotide in the broad population of patients treated with defibrotide for VOD/SOS, with or without MOD.

Acknowledgements Clinical analysis was funded by Jazz Pharmaceuticals. We thank Katherine Molnar-Kimber, PhD, and John Norwood of The Curry Rockefeller Group, LLC, of Tarrytown, NY, USA for providing medical writing and editorial support, which were funded by Jazz Pharmaceuticals in accordance with Good Publication Practice (GPP3) guidelines (http://www.ismpp.org/ gpp3). Jazz Pharmaceuticals also reviewed and edited the manuscript for scientific accuracy. We thank all of the study investigators, study staff, nursing teams, and patients for their participation in the clinical studies cited in this pooled analysis.

\section{Compliance with ethical standards}

Conflict of interest Paul G. Richardson has served on advisory committees and as a consultant, and received research funding from Jazz Pharmaceuticals. Saurabh Aggarwal and Ozlem Topaloglu are employees of Novel Health Strategies, which received funding from Jazz Pharmaceuticals for this analysis. Kathleen Villa is an employee of Jazz Pharmaceuticals and holds stock and/or stock options in Jazz Pharmaceuticals plc. Selim Corbacioglu has served as a consultant to and received honoraria from Gentium/Jazz Pharmaceuticals.

Publisher's note: Springer Nature remains neutral with regard to jurisdictional claims in published maps and institutional affiliations.

Open Access This article is licensed under a Creative Commons Attribution 4.0 International License, which permits use, sharing, adaptation, distribution and reproduction in any medium or format, as long as you give appropriate credit to the original author(s) and the source, provide a link to the Creative Commons license, and indicate if changes were made. The images or other third party material in this article are included in the article's Creative Commons license, unless indicated otherwise in a credit line to the material. If material is not included in the article's Creative Commons license and your intended use is not permitted by statutory regulation or exceeds the permitted use, you will need to obtain permission directly from the copyright holder. To view a copy of this license, visit http://creativecommons. org/licenses/by/4.0/.

\section{References}

1. Coppell JA, Richardson PG, Soiffer R, Martin PL, Kernan NA, Chen A, et al. Hepatic veno-occlusive disease following stem cell transplantation: incidence, clinical course, and outcome. Biol Blood Marrow Transplant. 2010;16:157-68.

2. Corbacioglu S, Hönig M, Lahr G, Stöhr S, Berry G, Friedrich $\mathrm{W}$, et al. Stem cell transplantation in children with infantile osteopetrosis is associated with a high incidence of VOD, which could be prevented with defibrotide. Bone Marrow Transplant. 2006;38:547-53.

3. Richardson PG, Riches ML, Kernan NA, Brochstein JA, Mineishi $S$, Termuhlen AM, et al. Phase 3 trial of defibrotide for the treatment of severe veno-occlusive disease and multi-organ failure. Blood. 2016;127:1656-65.

4. Strouse C, Richardson P, Prentice G, Korman S, Hume R, Nejadnik B, et al. Defibrotide for treatment of severe veno-occlusive disease in pediatrics and adults: an exploratory analysis using data from the Center for International Blood and Marrow Transplant Research. Biol Blood Marrow Transplant. 2016;22:1306-12.

5. Mohty M, Malard F, Abecassis M, Aerts E, Alaskar AS, Aljurf M, et al. Sinusoidal obstruction syndrome/veno-occlusive disease: current situation and perspectives-a position statement from the European Society for Blood and Marrow Transplantation (EBMT). Bone Marrow Transplant. 2015;50:781-9.

6. Carreras E, Diaz-Ricart M. The role of the endothelium in the short-term complications of hematopoietic SCT. Bone Marrow Transplant. 2011;46:1495-502.

7. Mohty M, Malard F, Abecassis M, Aerts E, Alaskar AS, Aljurf $M$, et al. Revised diagnosis and severity criteria for sinusoidal obstruction syndrome/veno-occlusive disease in adult patients: a new classification from the European Society for Blood and Marrow Transplantation. Bone Marrow Transplant. 2016;51:906-12.

8. Corbacioglu S, Carreras E, Ansari M, Balduzzi A, Cesaro S, Dalle $\mathrm{JH}$, et al. Diagnosis and severity criteria for sinusoidal obstruction syndrome/veno-occlusive disease in pediatric patients: a new classification from the European Society for Blood and Marrow Transplantation. Bone Marrow Transplant. 2018;53:138-45. 
9. Jones RJ, Lee KS, Beschorner WE, Vogel VG, Grochow LB, Braine $\mathrm{HG}$, et al. Venoocclusive disease of the liver following bone marrow transplantation. Transplantation. 1987;44:778-83.

10. Dignan FL, Wynn RF, Hadzic N, Karani J, Quaglia A, Pagliuca A, et al. Haemato-oncology Task Force of British Committee for Standards in Haematology; British Society for Blood and Marrow Transplantation. BCSH/BSBMT guideline: diagnosis and management of veno-occlusive disease (sinusoidal obstruction syndrome) following haematopoietic stem cell transplantation. Br J Haematol. 2013;163:444-57.

11. McDonald GB, Hinds MS, Fisher LD, Schoch HG, Wolford JL, Banaji $\mathrm{M}$, et al. Veno-occlusive disease of the liver and multiorgan failure after bone marrow transplantation: a cohort study of 355 patients. Ann Intern Med. 1993;118:255-67.

12. Carreras E, Bertz H, Arcese W, Vernant JP, Tomás JF, Hagglund $\mathrm{H}$, et al. Incidence and outcome of hepatic veno-occlusive disease after blood or marrow transplantation: a prospective cohort study of the European Group for Blood and Marrow Transplantation. European Group for Blood and Marrow Transplantation Chronic Leukemia Working Party. Blood. 1998;92:3599-604.

13. Yakushijin K, Atsuta Y, Doki N, Yokota A, Kanamori H, Miyamoto T, et al. Sinusoidal obstruction syndrome after allogeneic hematopoietic stem cell transplantation: Incidence, risk factors and outcomes. Bone Marrow Transplant. 2016; 51:403-9.

14. Carreras E, Díaz-Beyá M, Rosiñol L, Martínez C, FernándezAvilés F, Rovira M. The incidence of veno-occlusive disease following allogeneic hematopoietic stem cell transplantation has diminished and the outcome improved over the last decade. Biol Blood Marrow Transplant. 2011;17:1713-20.

15. Tsirigotis PD, Resnick IB, Avni B, Grisariu S, Stepensky P, Or R, et al. Incidence and risk factors for moderate-to-severe venoocclusive disease of the liver after allogeneic stem cell transplantation using a reduced intensity conditioning regimen. Bone Marrow Transplant. 2014;49:1389-92.

16. Defitelio (defibrotide sodium) injection [package insert on the Internet]. Palo Alto (CA): Jazz Pharmaceuticals, 2016. Available from: https://www.accessdata.fda.gov/drugsatfda_docs/label/ 2016/208114lbl.pdf.

17. Defitelio (defibrotide) [package insert on the Internet]. Villa Guardia (Italy): Gentium, 2016. Available from: http://www.ema.europa.eu/ docs/en_GB/document_library/EPAR_-_Product_Information/huma n/002393/WC500153150.pdf.

18. Pescador R, Capuzzi L, Mantovani M, Fulgenzi A, Ferrero ME. Defibrotide: properties and clinical use of an old/new drug. Vascul Pharmacol. 2013;59:1-10.

19. Palomo M, Diaz-Ricart M, Rovira M, Escolar G, Carreras E. Defibrotide prevents the activation of macrovascular and microvascular endothelia caused by soluble factors released to blood by autologous hematopoietic stem cell transplantation. Biol Blood Marrow Transplant. 2011;17:497-506.

20. Benimetskaya L, Wu S, Voskresenskiy AM, Echart C, Zhou JF, Shin J, et al. Angiogenesis alteration by defibrotide: implications for its mechanism of action in severe hepatic veno-occlusive disease. Blood. 2008;112:4343-52.

21. Echart CL, Graziadio B, Somaini S, Ferro LI, Richardson PG, Fareed J, et al. The fibrinolytic mechanism of defibrotide: effect of defibrotide on plasmin activity. Blood Coagul Fibrinolysis. 2009;20:627-34.

22. Palomo M, Mir E, Rovira M, Escolar G, Carreras E, Diaz-Ricart M. What is going on between defibrotide and endothelial cells? Snapshots reveal the hot spots of their romance. Blood. 2016;127:1719-27.

23. Corbacioglu S, Richardson PG. Defibrotide for children and adults with hepatic veno-occlusive disease post hematopoietic cell transplantation. Expert Rev Gastroenterol Hepatol. 2017;11:885-98.
24. Triplett BM, Kuttab HI, Kang G, Leung W. Escalation to highdose defibrotide in patients with hepatic veno-occlusive disease. Biol Blood Marrow Transplant. 2015;21:2148-53.

25. Pol RR, Russell N, Das-Gupta E, Watson L, Rachael L, Byrne J. Incidence and management of hepatic severe veno-occlusive disease in 273 patients in a single centre with defibrotide. Bone Marrow Transplant. 2016;51:1262-4.

26. Sucak GT, Aki ZS, Yagcí M, Yegin ZA, Ozkurt ZN, Haznedar R. Treatment of sinusoidal obstruction syndrome with defibrotide: a single-center experience. Transplant Proc. 2007;39:1558-63.

27. Richardson PG, Soiffer RJ, Antin JH, Uno H, Jin Z, Kurtzberg J, et al. Defibrotide for the treatment of severe hepatic venoocclusive disease and multiorgan failure after stem cell transplantation: a multicenter, randomized, dose-finding trial. Biol Blood Marrow Transplant. 2010;16:1005-17.

28. Richardson PG, Murakami C, Jin Z, Warren D, Momtaz P, Hoppensteadt D, et al. Multi-institutional use of defibrotide in 88 patients after stem cell transplantation with severe veno-occlusive disease and multisystem organ failure: response without significant toxicity in a high-risk population and factors predictive of outcome. Blood. 2002;100:4337-43.

29. Corbacioglu S, Greil J, Peters C, Wulffraat N, Laws HJ, Dilloo D, et al. Defibrotide in the treatment of children with veno-occlusive disease (VOD): a retrospective multicentre study demonstrates therapeutic efficacy upon early intervention. Bone Marrow Transplant. 2004;33:189-95.

30. Corbacioglu S, Carreras E, Mohty M, Pagliuca A, Boelens JJ, Damaj G, et al. Defibrotide for the treatment of hepatic venoocclusive disease: final results from the international compassionateuse program. Biol Blood Marrow Transplant. 2016;22:1874-82.

31. Chopra R, Eaton JD, Grassi A, Potter M, Shaw B, Salat C, et al. Defibrotide for the treatment of hepatic veno-occlusive disease: results of the European compassionate-use study. Br J Haematol. 2000;111:1122-9.

32. Bulley SR, Strahm B, Doyle J, Dupuis LL. Defibrotide for the treatment of hepatic veno-occlusive disease in children. Pediatr Blood Cancer. 2007;48:700-4.

33. Richardson PG, Elias AD, Krishnan A, Wheeler C, Nath R, Hoppensteadt $\mathrm{D}$, et al. Treatment of severe veno-occlusive disease with defibrotide: compassionate use results in response without significant toxicity in a high-risk population. Blood. 1998;92:737-44.

34. Ruiz Ramos J, Company Albir MJ, Favieres Puigcerver C, Marrero Álvarez P, Megias Vericat JE, Valero García S, et al. CP-129 Defibrotide for sinusoidal obstruction syndrome: a single centre experience. Eur J Hosp Pharm. 2014;21:A52.

35. Locatelli F, Faraci M, Cesaro S, Pagliara D, Fagioli F, Zecca Marco, et al. Defibrotide for the treatment of hepatic venoocclusive disease/sinusoidal obstruction syndrome following hematopoietic stem cell transplantation or chemotherapy-results from the Italian Therapeutic Use Protocol. Blood. 2015;126:3107.

36. Balade Martinez L, Valle LGD, Martin ER, De Sebastian Rueda M, Molia Cabezuelo M, Herrero Ambrosio A. CP-062 Defibrotide for the treatment of severe hepatic veno-occlusive disease. A single centre experience. Eur J Hosp Pharm. 2016;23:A27-A28.

37. Yakushijin K, Ikezoe T, Ohwade C, Kudo K, Okamura H, Goto $\mathrm{H}$, et al. Nationwide survey of defibrotide and recombinant human soluble thrombomodulin for treatment of sinusoidal obstruction syndrome after allogeneic hematopoietic stem cell transplantation. Bone Marrow Transplant. 2016;51:S77-S78.

38. Richardson P, Smith A, Triplett B, Kernan N, Grupp S, Antin J, et al. Final efficacy and safety results from a defibrotide expandedaccess program for patients with hepatic veno-occlusive disease/ sinusoidal obstruction syndrome. Bone Marrow Transplant. 2017;52:S64-S65.

39. Corbacioglu S, Grupp SA, Pagliuca A, Hume RL, Zhu J, Tappe W, et al. Protocol for a phase 3 , randomized, adaptive study comparing 
the efficacy and safety of defibrotide vs best supportive care to prevent hepatic veno-occlusive disease/sinusoidal obstruction syndrome in adult and pediatric patients undergoing hematopoietic stem cell transplant. Paper presented at ASH Meeting on Hematologic Malignancies; Chicago, IL; 2016; 16-17.

40. Kernan NA, Smith A, Triplett B, Lehmann L, Ryan RJ, Liang W, et al. Efficacy and safety of defibrotide in pediatric patients with veno-occlusive disease/sinusoidal obstruction syndrome (VOD/ SOS) after hematopoietic stem cell transplantation (HSCT): final results from the expanded-access program. Blood. 2017;130:1948.

41. Richardson PG, Antin JH, Giralt SA, Ryan RJ, Liang W, Hume RL, et al. Adults receiving defibrotide for the treatment of hepatic venoocclusive disease/sinusoidal obstruction syndrome (VOD/SOS) after hematopoietic stem cell transplantation (HSCT): final results from the expanded-access program. Blood. 2017;130:3225.

42. Richardson PG, Grupp SA, Pagliuca A, Krishnan A, Ho VT, Corbacioglu S. Defibrotide for the treatment of hepatic venoocclusive disease/sinusoidal obstruction syndrome with multiorgan failure. Int J Haematol Oncol. 2017;6:75-93.

43. Grupp S, Richardson PG, Kernan NA, Brochstein JA, Mineishi S, Termuhlen AM, et al. Defibrotide for the treatment of hepatic veno-occlusive disease/sinusoidal obstruction syndrome with multi-organ dysfunction: NNT for Day +100 survival and CR based on results from a pivotal, historically controlled, phase 3 trial. Pediatr Blood Cancer. 2016;63:S93.

44. Kernan NA, Grupp S, Smith AR, Arai S, Triplett B, Antin JH, et al. Final results from a defibrotide treatment-IND study for patients with hepatic veno-occlusive disease/sinusoidal obstruction syndrome. Br J Haematol. 2018;181:816-27.

45. Chalandon Y, Roosnek E, Mermillod B, Newton A, Ozsahin H, Wacker P, et al. Prevention of veno-occlusive disease with defibrotide after allogeneic stem cell transplantation. Biol Blood Marrow Transplant. 2004;10:347-54.

46. Dignan F, Gujral D, Ethell M, Evans S, Treleaven J, Morgan G, et al. Prophylactic defibrotide in allogeneic stem cell transplantation: minimal morbidity and zero mortality from veno-occlusive disease. Bone Marrow Transplant. 2007;40:79-82.

47. Qureshi A, Marshall L, Lancaster D. Defibrotide in the prevention and treatment of veno-occlusive disease in autologous and allogeneic stem cell transplantation in children. Pediatr Blood Cancer. 2008;50:831-2.

48. Corbacioglu S, Cesaro S, Faraci M, Balteau-Couanet D, Gruhn B, Rovelli A, et al. Defibrotide for prophylaxis of hepatic venoocclusive disease in paediatric haemopoietic stem-cell transplantation: an open-label, phase 3, randomised controlled trial. Lancet. 2012;379:1301-9.

49. Clinicaltrials.gov. NCT02851407: Study comparing efficacy and safety of defibrotide vs best supportive care in the prevention of hepatic veno-occlusive disease in adult and pediatric patients. Available from: https://clinicaltrials.gov/ct2/show/NCT02851407.

50. Dietrich CF, Trenker C, Fontanilla T, Görg C, Hausmann A, Klein $\mathrm{S}$, et al. New ultrasound techniques challenge the diagnosis of sinusoidal obstruction syndrome. Ultrasound Med Biol. 2018; 44:2171-82. 